\title{
Kimberly A. Rivers, Preaching the Memory of Virtue and Vice. Memory, Images, and Preaching in the Late Middle Ages
}

\section{G. Matteo Roccati}

\section{(2) OpenEdition}

\section{Journals}

Édition électronique

URL : https://journals.openedition.org/studifrancesi/3000

DOI : 10.4000/studifrancesi.3000

ISSN : 2421-5856

Éditeur

Rosenberg \& Sellier

Édition imprimée

Date de publication : 1 juillet 2013

Pagination : 430

ISSN : 0039-2944

\section{Référence électronique}

G. Matteo Roccati, « Kimberly A. Rivers, Preaching the Memory of Virtue and Vice. Memory, Images, and Preaching in the Late Middle Ages », Studi Francesi [En ligne], 170 (LVII | II) | 2013, mis en ligne le 30 novembre 2015, consulté le 02 février 2023. URL : http://journals.openedition.org/studifrancesi/3000 ; DOI : https://doi.org/10.4000/studifrancesi.3000

Ce document a été généré automatiquement le 2 février 2023.

\section{c) (†) $\odot$}

Creative Commons - Attribution - Pas d'Utilisation Commerciale - Pas de Modification 4.0 International - CC BY-NC-ND 4.0

https://creativecommons.org/licenses/by-nc-nd/4.0/ 


\title{
Kimberly A. Rivers, Preaching the Memory of Virtue and Vice. Memory, Images, and Preaching in the Late Middle Ages
}

\author{
G. Matteo Roccati
}

\section{RÉFÉRENCE}

KIMBERLY A. RIVERS, Preaching the Memory of Virtue and Vice. Memory, Images, and Preaching in the Late Middle Ages, Turnhout, Brepols, 2010 («Sermo: Studies on Patristic, Medieval, and Reformation Sermons and Preaching», 4), pp. XVIII-378.

1 L'ambition de cet ouvrage est de rendre compte de l'évolution entre le XII et le début $\mathrm{du} \mathrm{XV}^{\mathrm{e}}$ siècle de l'attitude à l'égard de la mémoire et des techniques de mémorisation, évolution induite par le développement des écoles et par les exigences pastorales des ordres mendiants. L'ouvrage s'articule en trois parties. La première est consacrée au $\mathrm{XII}^{\mathrm{e}}$ siècle, période de transition où s'affirme, en particulier chez les Dominicains et les Franciscains, une nouvelle approche, plus positive, à l'égard de la mémoire. Une attention spéciale est réservée aux écrits de Hugues de Saint Victor, Guibert de Tournai et David von Augsburg: les techniques mnémoniques héritées des pratiques pédagogiques et rhétoriques en usage depuis l'Antiquité, ainsi que la tradition monastique de la méditation à partir d'images mémorisées, sont repensées pour structurer l'écrit et pour les besoins de la prédication. La deuxième partie examine justement les arts de la prédication, avec une analyse détaillée de l'Ars praedicandi de Francesc Eiximenis, et la place que prend la référence aux images, notamment les images mythologiques des frères anglais «classicisants» du début du XIV siècle (Robert Holcot, John Ridevall). La troisième partie étudie la diffusion en Europe de ces images reliant les figures mythologiques et les vertus et vices chrétiens: en France chez Pierre 
Bersuire et Jean de Hesdin, dans les pays germaniques et en Europe centrale par le biais du Dormi secure de Johannes von Werden. Un dernier chapitre traite de la référence à la mémoire chez les prédicateurs italiens, en particulier chez Giovanni da San Gimignano et Bernardino da Siena. La bibliographie (pp. 337-365) et l'index (pp. 367-377) terminent le volume. 